\title{
Immunohistochemistry defined subtypes of breast cancer in 678 Sudanese and Eritrean women; hospitals based case series
}

\author{
Asmerom Tesfamariam Sengal ${ }^{1,2^{*}}$ D, Nada Suliman Haj-Mukhtar ${ }^{1}$, Ahmed Mohammed Elhaj ${ }^{3}$, Shahinaz Bedri ${ }^{4}$, \\ Eva Johanna Kantelhardt ${ }^{5}$ and Ahmed A. Mohamedani ${ }^{1}$
}

\begin{abstract}
Background: Breast cancer is the most common malignancy accounting for $25 \%$ of all cancers in females. In Africa, breast cancer prevalence and mortality are steadily increasing. Knowledge of hormone receptors and human epidermal growth factor receptor-2 (HER-2) expressions are vital for breast cancer management plans and decision making. There is wide regional variation in the proportion of these biomarkers, especially in African countries. Hormone receptors positivity in indigenous African and African American women is considered to be low and triple negative breast cancer is a dominant phenotype. There is paucity of data regarding hormone receptors (ER and PR) and HER2 expressions in North-eastern Africa (Eritrea and Sudan). The purpose of this study was to evaluate the expression of ER, PR and HER2 in Eritrean and Sudanese case series and correlate these biomarkers with the clinicopathological profile.
\end{abstract}

Method: Clinicopathologic data of patients were collected from clinical records. Immunohistochemistry biomarkers (ER, PR, and HER2) were assessed in consecutive female patients who had been diagnosed with invasive breast cancer from 2011 to 2015 in Gezira University Pathology Laboratory, the Sudan and National Health laboratory, Asmara, Eritrea.

Results: There were 678 cases involved in this study. The mean age was 48.8 years with \pm 0.53 standard error of the mean. Two-thirds of the case were $\leq 50$ years. Invasive ductal carcinoma, no special type was the most dominant histologic type (86\%) in both study groups. The majority of cases (70\%) had tumour stage pT2 and pT3 and about 50\% had lymph node involvement. Less than $5 \%$ of the cases had well-differentiated tumours. The ER, PR and HER2 positive rates were 45\%, 32\%, and 29\%, respectively. The proportion of luminal-A like, luminal-B like, HER2 enriched and TNBC were $37 \%, 13 \%, 16 \%$ and 34\%, respectively. Fisher extract analysis showed age $(p=.015)$, tumour size $(p=.041)$, and histologic grade $(p=.000)$ were significantly associated with intrinsic subtypes. Furthermore, Logistic regression analysis stratified by origin, age, tumour size, lymph-node metastasis and grade indicated that younger women age ( $\leq 50$ years) and grade III tumours were more likely to be diagnosed with ER negative breast cancer.

Conclusion: Most of Sudanese and Eritrean women were diagnosed at younger age and with unfavourable prognostic clinicopathologic prognostic markers. TNBC is more frequent in this cohort study; patients with grade III tumours and young age are more likely to be hormone receptors negative. Therefore, routine determination of hormone receptors is warranted for appropriate targeted therapy.

Keywords: Hormone receptor, Breast cancer subtype, Immunohistochemistry, Sudan, Eritrea and Africa

\footnotetext{
* Correspondence: asmeromp@gmail.com

${ }^{1}$ Pathology Department, Faculty of Medicine, University of Gezira,

Wad-Medani, Gezira, Sudan

${ }^{2}$ Orotta School of Medicine and Dentistry, Asmara, Eritrea

Full list of author information is available at the end of the article
}

(c) The Author(s). 2017 Open Access This article is distributed under the terms of the Creative Commons Attribution 4.0 International License (http://creativecommons.org/licenses/by/4.0/), which permits unrestricted use, distribution, and reproduction in any medium, provided you give appropriate credit to the original author(s) and the source, provide a link to the Creative Commons license, and indicate if changes were made. The Creative Commons Public Domain Dedication waiver (http://creativecommons.org/publicdomain/zero/1.0/) applies to the data made available in this article, unless otherwise stated. 


\section{Background}

Breast cancer (BC) is the most prevalent cancer in women accounting for one fourth of all cancers and is the second cause of cancer-related death in both developed and most developing countries [1-3]. In Africa, the incidence of $\mathrm{BC}$ is relatively low compared to the western developed countries however, mortality rates are alarmingly high. Epidemiological data from Surveillance, Epidemiology, and End Results (SEER) documented a gradual drop in $\mathrm{BC}$ incidence and mortality in white American but a steady increase in black American women [4]. BC is a heterogeneous disease both in clinical and pathological profiles. There is a wide variation in clinical presentation, histologic type, molecular biomarkers, prognosis, and treatment outcome.

$\mathrm{BC}$ in African and African American (AA) women has been reported to be a more aggressive disease $[5,6]$. Many studies showed women with $\mathrm{BC}$ in native African, African in diaspora and AA had been diagnosed at a younger age, with higher histologic grade, advanced stage and with higher hormone receptor (HR) negative proportions than white women [5, 7-10]. A recent, investigation revealed unique genetic polymorphisms that are associated with hormone receptor negative $\mathrm{BC}$ in African American women.

Hormone receptors (oestrogen receptor (ER) and progesterone receptor (PR)) and human epidermal growth factor receptor-2 (HER2) are the most relevant clinical biomarkers that are widely used in stratifying $\mathrm{BC}$ cases management. The rate of ER, PR, and HER2 of $\mathrm{BC}$ varies from region to region. Patients with $\mathrm{HR}$ positivity have a better prognosis and are eligible for hormonal targeted therapy. The prevalence of these biomarkers is inconsistent and there is wide variation among ethnicities. A meta-analysis review in indigenous African women reported a wide range of ER positive BC (40 to $80 \%$ in North Africa and 20 to70\% in West Africa) [11]. It is also reported AA women with $\mathrm{BC}$ had less ER/PR positive tumours compared to Caucasian women. In general, African women have higher $\mathrm{HR}$ negative $\mathrm{BC}$ tumours [12] compared to other races although a recent data reported an increasing trend in some African countries $[13,14]$.

Perou and colleagues clustered breast cancer based on DNA microarray signature into luminal-A, luminal B, HER2 enriched, basal like and normal like [15]. Following to this investigation, many studies classified $\mathrm{BC}$ molecular subtypes using IHC surrogate markers in a similar way to the DNA microarray clustering [16]. The luminal A (ER+ and/or PR+ and HER2 -) is more common in older Caucasian women and has superior prognosis and treatment outcome. Luminal B (ER+, PR+ and HER2+) is also common in white women and has a worse prognosis compared to luminal-A, but better than the HER2 enriched and basal like [17]. HER2 enriched is more aggressive and common in younger women but with the introduction of targeted therapy anti- HER2 (Herceptin, monoclonal antibody) the outcome of $\mathrm{BC}$ patients expressing HER2 slightly improved. The basal like is $80 \%$ concordant to the triple negative $\mathrm{BC}$ (TNBC); it is more common in indigenous African women and young African American women and has poorest prognosis and treatment outcome $[18,19]$.

Despite the growing descriptive studies which are mostly based on IHC markers of HR and HER2 expression evaluation, the detailed genetic landscape of breast cancer in indigenous African women is poorly investigated.

The distribution of the receptor defined BC subtypes in Africa is highly variable like the ER and PR rate. Although a number of studies reported the TNBC is most common molecular subtype in Africa [20] a recent study reported breast cancer in West African women is different from Eastern African women. For instance, one study documented Ethiopian women with breast cancer have comparable percentage of luminal-A subtype to those white Americans [5]. On the other hand, Western African women from Ghana have more TNBC as compared to Ethiopian and White American women [5]. There is also regional difference in the proportion of subtype of $\mathrm{BC}$ within one country. Awadelkerim et al. reported a high rate of $\mathrm{HR}$ positive subtype which is comparable to white Caucasian women (Italian) [21]. Our cohort study and a recent report from Khartoum found HR negative BCs are more prevalent in Sudanese women [22]. There is a huge disparity in HR status and molecular subtypes of breast cancer among nations and within a nation. What contributes to regional and racial differences in the proportion of molecular subtypes of $\mathrm{BC}$ is not clear. It is crucial to know the distribution of ER/PR and HER2 expression and their derived BC subtypes in outlining strategic BC management plans in this region. Due to limited resources, ER/PR and HER2 determination are not done routinely in clinical practice in Eritrea and Sudan. The purpose of this study was to investigate the expression of ER, PR, HER2 and receptor defined molecular subtypes in north-east African women (Sudanese and Eritrean) and analyse the correlation of clinical and histologic markers with HR status and molecular subtypes.

\section{Methods \\ Data collection}

Ethical approval was obtained from the research ethics committees of both institutions (University of Gezira and Orotta School of Medicine and Dentistry). Clinical data were retrieved using a standard protocol from the histopathology department of the University of Gezira (UOG), Gezira, Sudan and Orotta School of Medicine 
and Dentistry (OSMD) in National health laboratory, Asmara, Eritrea. This study was a retrospective facility based consecutive case series from 2011 to 2015 with histologically confirmed invasive breast carcinoma and not treated previously. Demographic data and tumour characteristics were obtained from medical records and hormone receptor status ER, PR and HER2 expressions were determined using standard IHC method. Tumour grade was assessed according to the modified Nottingham Bloom-Richardson grading system [23]. Tumour size and nodal status were described according to the TNM classification [24].

\section{Study setting}

Eritrea and Sudan are located in the Northeast of Africa. Eritrea has six million people and has only one national Anatomic-pathology department where all clinical histology and cytology are assessed. Sudan is the largest country in Africa with more than 40 million people. Sudan has diverse ethnic groups including Afro, Arab and Afro-Arab tribes. Gezira state has about four million inhabitants; the University of Gezira histopathology laboratory is the only public institution serving this state and other nearby states. There is no radio/chemotherapy centre in Eritrea. But Sudan has two public oncology hospitals located in Khartoum and Wad-Medani (Gezira). The national cancer institute of Gezira state was established in 1999 and serves for almost half of the country including some referral cases from Eritrea.

\section{Immunohistochemistry}

For both Sudanese and Eritrean cohort case series, ER, $\mathrm{PR}$, and HER2 immunostaining was performed manually in University of Gezira (UG), pathology laboratory, Wad-Medani, Sudan and National health laboratory (NHL) pathology department, Asmara, Eritrea, respectively. In brief, formalin-fixed paraffin-embedded (FFPE) breast tumour blocks were obtained from pathology department of UG and NHL. FFPE tissues were sectioned serially into $4 \mu \mathrm{m}$ and placed in frosted microscopic slides and deparaffinized in series of xylene (three changes), graded alcohol ( 2 changes $100 \%, 90 \%$, and $70 \%$ ethanol) and rehydrated in distilled water. Antigen retrieval was performed using a water bath in $10 \mathrm{mM}$ citrate buffer $(\mathrm{pH} 6.0)$ at $95{ }^{\circ} \mathrm{C}$ for $45 \mathrm{~min}$. Then washed with Tris Buffered Saline and blocked with 3\% hydrogen peroxide in Phosphate Buffered Saline. After that tissue sections were blocked with background snipper using a blocking agent (Biogenex, UK). Then incubated for $1 \mathrm{~h}$ with primary antibodies at room temperature: anti-ER (clone EPR703, Biogenex UK), anti-PR (clone PR88, Biogenex Ltd., UK), and anti-HER2neu (clone CB11), followed by biotinylated horse anti-mouse or goat anti-rabbit secondary antibodies. Staining was visualized using Diaminobenzadine $(\mathrm{DAB})$ and counterstained with haematoxylin.
ER and PR were considered positive if $\geq 1 \%$ nuclei of tumour cells were stained as per the American Society College Oncology/College American Pathology (ASCO/ CAP) guidelines [25] for both Sudanese and Eritrean women. HER2 was scored as $0,1+, 2+$, or $3+$ and FISH was not done for equivocal (2+) HER2 results in both groups and only with score $3+$ was considered HER2 positive and $\leq 2+$ score was assumed HER2 negative. Molecular breast cancer subtypes were defined using combination of these IHC markers as follows: luminal A-like (ER positive and/or PR positive and HER2 negative), luminal B-like (ER positive and/or PR positive/PR negative and HER2 positive), HER2 enriched type (ER negative, PR negative, HER2 positive), and triple negative (ER, PR, and HER2 negative) [13, 26, 27].

\section{Data analysis}

Data analysis was performed using SPSS version 21. Tumour characteristics and biomarkers of Sudanese and Eritrean women were compared across the BC subtypes using the chi-squared $\left(\mathrm{X}^{2}\right)$ test for categorical variables. Logistic regression analysis was used to determine the odd ratio (OR) or relative risk to evaluate the effect of age, histologic type, tumour size, lymph node metastasis and Nottingham histologic grade on a probability of ERnegative tumours or tumour subtypes. All $p$-values were calculated based on two-tailed tests of significance, where $p<0.05$ was considered statistically significant.

\section{Results}

A total of 678 patients (116 Eritrean and 562 Sudanese women) were included in this study. The age ranged from 20 to 90 with a mean age at diagnosis 48.8 years with the standard error of the mean (SEM) \pm 0.53 . Twothirds of patients were under 50 years and age category distribution is presented in (Fig. 1). The peak age category was $40-51$ years.

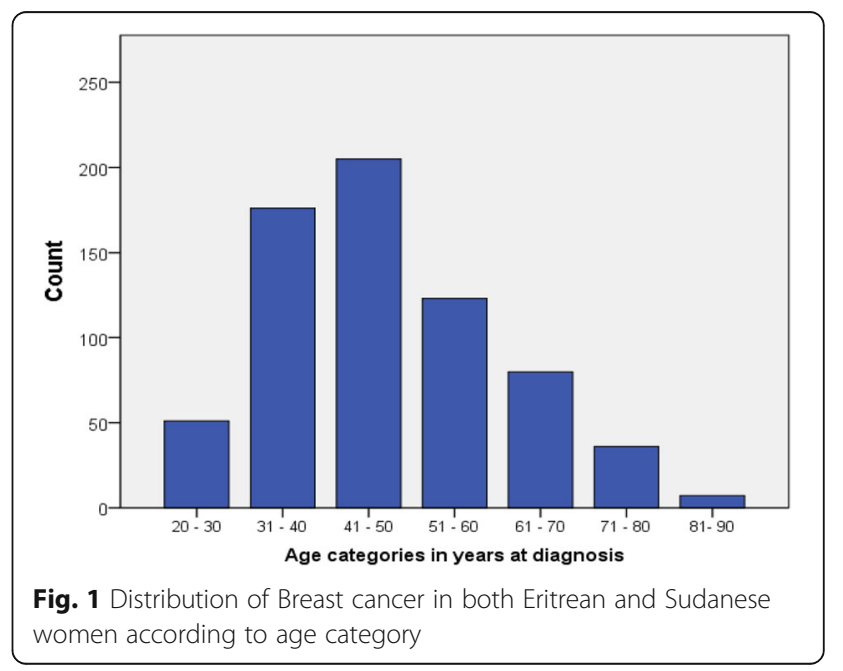


The proportion of tumour characteristics, HR status and IHC defined molecular subtypes of both groups are summarized in Table 1.

The most common morphologic type of breast cancer in this study cohort was invasive ductal carcinoma no special type (NST). Invasive lobular carcinomas account for less $5 \%$ when combining both study groups $(3.2 \%$ in Sudanese and $10 \%$ in Eritrean women). About $16 \%$ had tumour size less than $2 \mathrm{~cm}$ (pT1) and about one third had tumour size greater than $5 \mathrm{~cm}$ (pT3and pT4). Half of the patients had lymph node metastasis and only $35.5 \%$ had lymphovascular invasion (LVI). About $96 \%$ of patients were diagnosed with moderate to poorly differentiated (grade II/III) tumours. Of note, half of the Eritrean and $44 \%$ of Sudanese women presented with grade III (Table 1).

In regard to $\mathrm{HR}$ status, $54 \%$ women with $\mathrm{BC}$ were negative for ER and/or PR. The proportions in ER negative were similar in both study group; $51 \%$ and $55 \%$ for Eritrean and Sudanese women, respectively. For grade I cases, $75 \%$ (24/32) were ER positive. Similarly, (25/28) of ILC were positive for ER merging both groups (Table 2).

HER2 negative rate was the same in both Eritrean and Sudanese women (71\%). In 147 Sudanese cases, HER2 was not determined due to inadequate tissue for assessment. Data analysis was made removing these cases to

Table 1 proportion of clinicopathologic and IHC defined subtypes of BC in Eritrean and Sudanese women

\begin{tabular}{|c|c|c|c|c|c|c|c|}
\hline \multirow[t]{3}{*}{ Clinical and tumour characteristics } & & \multicolumn{4}{|c|}{ Origin } & \multirow{2}{*}{\multicolumn{2}{|c|}{$\begin{array}{l}\text { Combined both } \\
\text { study groups }\end{array}$}} \\
\hline & & \multicolumn{2}{|c|}{ Eritrean } & \multicolumn{2}{|c|}{ Sudanese } & & \\
\hline & & $n$ & $\%$ & $n$ & $\%$ & $n$ & $\%$ \\
\hline \multirow[t]{3}{*}{ Histologic type } & IDCNST & 89 & $76.7 \%$ & 492 & $87.9 \%$ & 581 & $85.9 \%$ \\
\hline & ILC & 11 & $9.5 \%$ & 18 & $3.2 \%$ & 29 & $4.3 \%$ \\
\hline & others & 16 & $13.8 \%$ & 50 & $8.9 \%$ & 66 & $9.8 \%$ \\
\hline \multirow[t]{4}{*}{ Pathologic tumour size } & pT1 & 23 & $19.8 \%$ & 82 & $15.5 \%$ & 105 & $16.3 \%$ \\
\hline & pT2 & 48 & $41.4 \%$ & 248 & $47.0 \%$ & 296 & $46.0 \%$ \\
\hline & pT3 & 37 & $31.9 \%$ & 118 & $22.3 \%$ & 155 & $24.1 \%$ \\
\hline & pT4 & 8 & $6.9 \%$ & 80 & $15.2 \%$ & 88 & $13.7 \%$ \\
\hline \multirow[t]{4}{*}{ LN involvement } & pNO & 72 & $62.1 \%$ & 198 & $47.3 \%$ & 270 & $50.5 \%$ \\
\hline & $\mathrm{pN} 1(1-3)$ & 15 & $12.9 \%$ & 86 & $20.5 \%$ & 101 & $18.9 \%$ \\
\hline & pN2(3-9) & 16 & $13.8 \%$ & 78 & $18.6 \%$ & 94 & $17.6 \%$ \\
\hline & $\mathrm{pN} 3(>9)$ & 13 & $11.2 \%$ & 57 & $13.6 \%$ & 70 & $13.1 \%$ \\
\hline \multirow[t]{3}{*}{ Grading } & $\mathrm{Gl}$ & 10 & $8.6 \%$ & 20 & $3.6 \%$ & 30 & $4.4 \%$ \\
\hline & Gll & 46 & $39.7 \%$ & 306 & $54.6 \%$ & 352 & $52.1 \%$ \\
\hline & GIII & 60 & $51.7 \%$ & 234 & $41.8 \%$ & 294 & $43.5 \%$ \\
\hline \multirow[t]{3}{*}{ LVI } & NO & 44 & $37.9 \%$ & 264 & $46.9 \%$ & 308 & $45.2 \%$ \\
\hline & unknown & 6 & $5.1 \%$ & 111 & $19.8 \%$ & 117 & $17.3 \%$ \\
\hline & YES & 56 & $48.3 \%$ & 185 & $15.2 \%$ & 102 & $35.5 \%$ \\
\hline \multirow[t]{2}{*}{ ER } & ER negative. & 59 & $50.9 \%$ & 308 & $55.0 \%$ & 367 & $54.3 \%$ \\
\hline & ER positive. & 57 & $49.1 \%$ & 252 & $45.0 \%$ & 309 & $45.7 \%$ \\
\hline \multirow[t]{2}{*}{$P R$} & PR negative & 69 & $59.5 \%$ & 346 & $61.8 \%$ & 415 & $61.4 \%$ \\
\hline & PR positive & 47 & $40.5 \%$ & 214 & $38.2 \%$ & 261 & $38.6 \%$ \\
\hline \multirow[t]{2}{*}{$\mathrm{HR}$} & HR positive & 57 & $49.1 \%$ & 257 & $45.9 \%$ & 314 & $46.4 \%$ \\
\hline & HR negative & 59 & $50.9 \%$ & 303 & $54.1 \%$ & 362 & $53.6 \%$ \\
\hline \multirow[t]{3}{*}{ HER2 } & negative & 82 & $70.7 \%$ & 296 & $71.3 \%$ & 378 & $71.2 \%$ \\
\hline & positive & 34 & $29.3 \%$ & 119 & $28.7 \%$ & 153 & $28.8 \%$ \\
\hline & Missing & 0 & 0 & 147 & - & 147 & - \\
\hline \multirow[t]{4}{*}{ IHC based breast cancer subtype } & Luminal A-like & 43 & $37.1 \%$ & 153 & $36.9 \%$ & 196 & $36.9 \%$ \\
\hline & Luminal B-like & 14 & $12.1 \%$ & 54 & $13.0 \%$ & 68 & $12.8 \%$ \\
\hline & HER2 enriched & 20 & $17.2 \%$ & 65 & $15.7 \%$ & 85 & $16.0 \%$ \\
\hline & TNBC & 39 & $33.6 \%$ & 143 & $34.5 \%$ & 182 & $34.3 \%$ \\
\hline
\end{tabular}


Table 2 ER and PR proportion according to tumour characteristic in both Eritrean and Sudanese women

\begin{tabular}{|c|c|c|c|c|c|c|c|c|c|}
\hline \multicolumn{2}{|c|}{ Tumour and biomarker characteristics } & \multicolumn{4}{|c|}{ Eritrean } & \multicolumn{4}{|c|}{ Sudanese } \\
\hline & & \multicolumn{2}{|c|}{ ER positive } & \multicolumn{2}{|c|}{ ER negative } & \multicolumn{2}{|c|}{ ER positive } & \multicolumn{2}{|c|}{ ER negative } \\
\hline & & $n$ & (\%) & $n$ & $(\%)$ & $n$ & $(\%)$ & $n$ & $(\%)$ \\
\hline \multirow[t]{3}{*}{ Histologic type } & IDCNST & 41 & $71.9 \%$ & 48 & $81.4 \%$ & 222 & $83.6 \%$ & 270 & $91.5 \%$ \\
\hline & ILC & 10 & $17.5 \%$ & 1 & $1.7 \%$ & 15 & $5.7 \%$ & 3 & $1 \%$ \\
\hline & Others & 6 & $10.5 \%$ & 10 & $16.9 \%$ & 27 & $10.7 \%$ & 23 & $7.5 \%$ \\
\hline \multirow[t]{4}{*}{ Pathologic Tumour size } & pT1 & 17 & $29.8 \%$ & 6 & $10.2 \%$ & 46 & $19.2 \%$ & 36 & $12.5 \%$ \\
\hline & pT2 & 26 & $45.6 \%$ & 22 & $37.3 \%$ & 107 & $44.6 \%$ & 141 & $49.0 \%$ \\
\hline & pT3 & 10 & $17.5 \%$ & 27 & $45.8 \%$ & 50 & $20.8 \%$ & 68 & $23.6 \%$ \\
\hline & pT4 & 4 & $7.0 \%$ & 4 & $6.8 \%$ & 37 & $15.4 \%$ & 43 & $14.9 \%$ \\
\hline \multirow[t]{4}{*}{ Lymph node involvement } & pNO & 40 & $70.2 \%$ & 32 & $54.2 \%$ & 104 & $52.0 \%$ & 94 & $42.9 \%$ \\
\hline & $\mathrm{pN} 1$ & 6 & $10.5 \%$ & 9 & $15.3 \%$ & 37 & $18.5 \%$ & 49 & $22.4 \%$ \\
\hline & pN2 & 8 & $14.0 \%$ & 8 & $13.6 \%$ & 36 & $18.0 \%$ & 42 & $19.2 \%$ \\
\hline & pN3 & 3 & $5.3 \%$ & 10 & $16.9 \%$ & 23 & $11.5 \%$ & 34 & $15.5 \%$ \\
\hline \multirow[t]{3}{*}{ Nottingham Grade } & Gl & 8 & $14.0 \%$ & 2 & $3.4 \%$ & 16 & $6.3 \%$ & 4 & $1.3 \%$ \\
\hline & Gll & 30 & $52.6 \%$ & 16 & $27.1 \%$ & 155 & $61.5 \%$ & 151 & $49.0 \%$ \\
\hline & GIII & 19 & $33.3 \%$ & 41 & $69.5 \%$ & 81 & $32.1 \%$ & 153 & $49.7 \%$ \\
\hline \multirow[t]{2}{*}{$P R$} & PR negative & 10 & $17.5 \%$ & 59 & $100.0 \%$ & 43 & $17.1 \%$ & 303 & $98.4 \%$ \\
\hline & PR positive & 47 & $82.5 \%$ & 0 & $0.0 \%$ & 209 & $82.9 \%$ & 5 & $1.6 \%$ \\
\hline \multirow[t]{3}{*}{ HER 2} & Negative $(0$ and $1+)$ & 37 & $64.9 \%$ & 29 & $49.2 \%$ & 132 & $65.1 \%$ & 112 & $52.8 \%$ \\
\hline & Negative $(2+)$ & 6 & $10.5 \%$ & 10 & 16.9 & 20 & $9.8 \%$ & 32 & $15.1 \%$ \\
\hline & Positive (3+) & 14 & $24.6 \%$ & 20 & $33.9 \%$ & 51 & $25.1 \%$ & 68 & $32.1 \%$ \\
\hline
\end{tabular}

IDCNST invasive ductal carcinoma, no special type, ILC invasive lobular carcinoma

determine the proportion positive, negative and equivocal results for HER2 in Table 2 and the same approach was used for subtyping. Interestingly, the percentage of molecular subtypes of $\mathrm{BC}$ in both countries was quite same (Tables 1 and 3). Nearly one-third (37\%) had luminal-A like and $34 \%$ of women were TNBC, which have superior and poor prognosis, respectively. The majority of TNBC were grade II or III and larger tumour size, while patients with luminal-A like had well to moderately differentiated tumours and smaller tumour size (Fig. 2 and Table 3).

There was significant association between age $(p=$ $0.015)$, pathologic tumour size $(P=0.041)$ and histologic grade $(p=.000)$ with the $\mathrm{BC}$ subtypes but no association was found with nationality/origin $(p=0.924)$, histologic type ( $p=0.056)$, and lymph node involvement $(p=0.058)$ as show in (Table 3 ). We noted some special type like medullary and papillary histologic types were TNBCs and histologic types of lobular and mucinous carcinomas were HR positive (data not shown).

Furthermore, multivariate logistic regression analysis stratified by age, origin, tumour size, lymph node status and grade also revealed no association between origin, histologic type and lymph node involvement with ER negativity. On the other hand, younger age ( $\leq 50$ years)
$(P=0.039, \mathrm{OR}=1.50,95 \mathrm{CI} 1.02-2.15), \mathrm{pT} 3$ and Nottingham grade III were significantly associated with ER negative BC ( $p=.000$, OR $2.2,95 \%$ CI $1.5-3.2)$ (Table 4$)$.

\section{Discussion}

Our cohort study is presenting a large case series data from northeast Sub-Saharan Africa (Eritrea and Sudan) countries. This region is a disadvantaged region with inadequate oncology service. There are no cancer screening programs and prevention strategies aiming in cancer reduction in this region [28]. $\mathrm{BC}$ account for more than $25 \%$ of all cancers in Eritrea [29] and an equal figure of deaths was estimated by WHO in this region [30]. This study indicated that majority of women in this region with $\mathrm{BC}$ were diagnosed at younger age ( $\leq 50$ years) with mean age 48.8 years consistent with previous reports in Africa [31]. Invasive ductal carcinoma (NST) was the most dominant histologic type, and nearly half of patients had lymph node involvement. ILC often express $\mathrm{HR}$ and has good prognosis is less frequent and especially in Sudanese women. Our study revealed less than $5 \%$ of women with BC have well-differentiated tumours and the majority had T2 or T3 tumour stage. Similar findings have been reported from Khartoum [21] and in native African women [31, 32]. Generally, aggressive 
Table 3 Association of demographic and clinicopathologic profiles with IHC defined subtypes of BC in both Eritrean and Sudanese women

\begin{tabular}{|c|c|c|c|c|c|c|c|c|c|c|}
\hline \multicolumn{2}{|c|}{ Demographic and tumour characteristics } & \multicolumn{8}{|c|}{ IHC defined breast cancer subtypes } & \multirow[t]{3}{*}{$P$ value } \\
\hline & & \multicolumn{2}{|c|}{ Luminal A } & \multicolumn{2}{|c|}{ Luminal B } & \multicolumn{2}{|c|}{ HER2 enriched } & \multicolumn{2}{|c|}{ TNBC } & \\
\hline & & $\mathrm{n}$ & $\%$ & $\mathrm{n}$ & $\%$ & $\mathrm{n}$ & $\%$ & $\mathrm{n}$ & $\%$ & \\
\hline \multirow[t]{2}{*}{ Age in years } & $\leq 50$ & 131 & $37.1 \%$ & 35 & $9.9 \%$ & 53 & $15.0 \%$ & 134 & $38.0 \%$ & 0.015 \\
\hline & $>50$ & 65 & $32.3 \%$ & 35 & $17.4 \%$ & 40 & $19.9 \%$ & 61 & $30.3 \%$ & \\
\hline \multirow[t]{2}{*}{ Nationality } & Sudanese & 153 & $35.0 \%$ & 56 & $12.8 \%$ & 73 & $16.7 \%$ & 155 & $35.5 \%$ & 0.924 \\
\hline & Eritrean & 42 & $36.2 \%$ & 14 & $12.1 \%$ & 20 & $17.2 \%$ & 40 & $34.5 \%$ & \\
\hline \multirow[t]{6}{*}{ Histologic type } & ${ }^{\mathrm{a}} \mathrm{IDCNST}$ & 159 & $33.3 \%$ & 65 & $13.6 \%$ & 85 & $17.8 \%$ & 168 & $35.2 \%$ & 0.056 \\
\hline & bILC & 16 & $61.5 \%$ & 1 & $3.8 \%$ & 5 & $19.2 \%$ & 4 & $15.4 \%$ & \\
\hline & Medullary & 0 & $0.0 \%$ & 0 & $0.0 \%$ & 0 & $0.0 \%$ & 13 & $100.0 \%$ & \\
\hline & Mucinous & 16 & $94.1 \%$ & 1 & $5.9 \%$ & 0 & $0.0 \%$ & 0 & $0.0 \%$ & \\
\hline & Papillary & 1 & $6.7 \%$ & 3 & $20.0 \%$ & 2 & $13.3 \%$ & 9 & $60.0 \%$ & \\
\hline & Cribriform & 4 & $100.0 \%$ & 0 & $0.0 \%$ & 0 & $0.0 \%$ & 0 & $0.0 \%$ & \\
\hline \multirow[t]{4}{*}{ Pathologic tumour size } & pT1 & 45 & $47.9 \%$ & 14 & $14.9 \%$ & 10 & $10.6 \%$ & 25 & $26.6 \%$ & .041 \\
\hline & pT2 & 74 & $31.1 \%$ & 35 & $14.7 \%$ & 48 & $20.2 \%$ & 81 & $34.0 \%$ & \\
\hline & pT3 & 43 & $31.2 \%$ & 13 & $9.4 \%$ & 23 & $16.7 \%$ & 59 & $42.8 \%$ & \\
\hline & pT4 & 27 & $40.3 \%$ & 7 & $10.4 \%$ & 9 & $13.4 \%$ & 24 & $35.8 \%$ & \\
\hline \multirow[t]{4}{*}{ Lymph Node involvement } & pNO & 102 & $42.7 \%$ & 31 & $13.0 \%$ & 34 & $14.2 \%$ & 72 & $30.1 \%$ & 0.58 \\
\hline & $\mathrm{pN} 1$ & 22 & $27.5 \%$ & 10 & $12.5 \%$ & 19 & $23.8 \%$ & 29 & $36.3 \%$ & \\
\hline & pN2 & 25 & $29.8 \%$ & 15 & $17.9 \%$ & 14 & $16.7 \%$ & 30 & $35.7 \%$ & \\
\hline & pN3 & 12 & $21.4 \%$ & 8 & $14.3 \%$ & 7 & $12.5 \%$ & 29 & $51.8 \%$ & \\
\hline \multirow[t]{3}{*}{ Nottingham Grade } & Gl & 19 & $67.9 \%$ & 3 & $10.7 \%$ & 4 & $14.3 \%$ & 2 & $7.1 \%$ & 0.000 \\
\hline & GII & 123 & $45.7 \%$ & 25 & $9.3 \%$ & 36 & $13.4 \%$ & 85 & $31.6 \%$ & \\
\hline & GIII & 54 & $21.0 \%$ & 42 & $16.3 \%$ & 53 & $20.6 \%$ & 108 & $42.0 \%$ & \\
\hline
\end{tabular}

${ }^{\mathrm{a}}$ IDCNST $=$ invasive ductal carcinoma, no special type, ${ }^{\mathrm{b}} / L C=$ invasive lobular carcinoma

clinical markers of $\mathrm{BC}$ are a common phenomenon in most developing countries. This could be partially due lack of screening and late diagnosis or some intrinsic biologic factors that have not yet been addressed.

Knowledge of hormone receptor and molecular subtype in a certain population is crucial in implementing breast cancer treatment plans. We found more than half

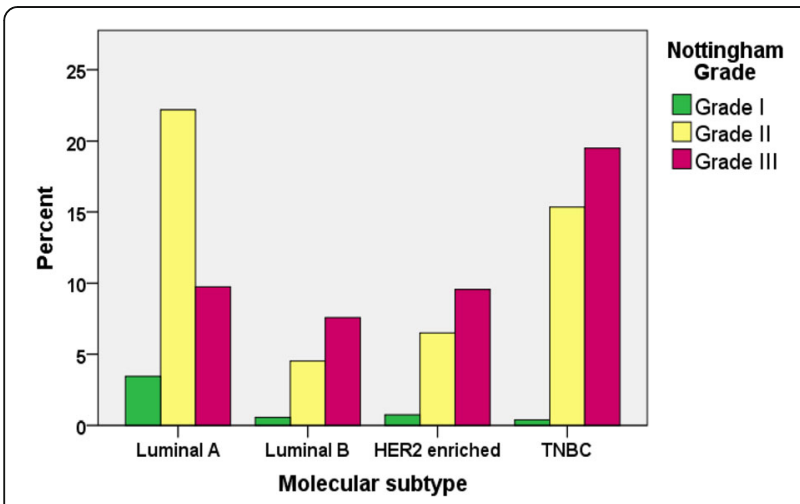

Fig. 2 Distribution of $I H C$ defined intrinsic subtypes of BC according to grade in both Eritrean and Sudanese women
(54\%) of women with BC had ER negative and 62\% PR negative. Our result is remarkably lower compared with the finding from West African women [33-35], Tunisia [36] Uganda [37] but much higher as compared with those reported from Egypt [38], Ethiopia [39], South African women [13] and Caucasian women in the west. Our finding is also different from previously reported in Central Sudan (Khartoum) [21] but similar to a recent report by Eltaib et al. [22]. The former study was small sample size, with a possible intrinsic bias and might not represent the actual population.

Multivariate logistic regression analysis in our study showed younger women (age $\leq 50$ years) are more likely to develop ER negative $\mathrm{BC}(P=0.039, \mathrm{OR}=$ 1.50, $95 \%$ CI 1.02-2.15). Similarly, grade III tumours are two times higher than grade I or II $(p=.000$, OR 2.2, 95\% CI 1.5-3.2). This finding is consistent with previous studies that younger premenopausal women ( $<50$ Years) and poorly differentiated $\mathrm{BC}$ is more likely to be HR negative [40]. The triad of poor clinical markers (young age, HR negative and poorly differentiated tumour) are common features in many African women with BC. 
Table 4 Multivariate logistic regression analysis for relative risk ratio of ER negative BC stratified by age, origin, pathologic tumour size, lymph-node metastasis and grade in both groups of cohort study (Eritrean and Sudanese women)

\begin{tabular}{|c|c|c|c|c|c|}
\hline \multicolumn{2}{|c|}{ Clinical and tumour characteristics } & \multirow{3}{*}{$\begin{array}{l}p \text {-value } \\
.039\end{array}$} & \multirow{3}{*}{$\begin{array}{l}\text { Risk ratio } \\
1.480\end{array}$} & \multicolumn{2}{|c|}{ 95\% Confidence interval } \\
\hline & & & & \multirow{2}{*}{$\frac{\text { Lower }}{1.019}$} & \multirow{2}{*}{$\begin{array}{l}\text { Upper } \\
2.149\end{array}$} \\
\hline Age in years & Age $\leq 50$ compared to $>50$ & & & & \\
\hline Origin & Eritrean (reference Sudanese) & .956 & .988 & .634 & 1.537 \\
\hline \multirow[t]{3}{*}{ Histologic type } & aDCNST (reference) & .198 & & & \\
\hline & Invasive lobular carcinoma & .051 & .847 & .780 & 1.211 \\
\hline & other & .532 & .833 & .469 & 1.479 \\
\hline \multirow[t]{4}{*}{ Pathologic Tumour size } & pT1 (reference) & .081 & & & \\
\hline & pT2 & .154 & 1.438 & .873 & 2.368 \\
\hline & pT3 & .013 & 2.050 & 1.162 & 3.615 \\
\hline & pT4 & .632 & 1.194 & .577 & 2.471 \\
\hline \multirow[t]{4}{*}{ Lymph Node involvement } & pNO (reference) & .306 & & & \\
\hline & $\mathrm{pN} 1$ & .149 & 1.432 & .880 & 2.332 \\
\hline & $\mathrm{pN} 2$ & .694 & 1.106 & .670 & 1.823 \\
\hline & pN3 & .133 & 1.556 & .875 & 2.768 \\
\hline Grade & GIII (Gl/II reference) & .000 & 2.203 & 1.534 & 3.164 \\
\hline
\end{tabular}

a IDCNST = invasive ductal carcinoma, no special type

Another remarkable finding in this study is higher proportion of TNBC which accounted for $34 \%$ in both study groups. Our result is in agreement with many reports from African studies and other developing countries [41]. This finding is almost the same with $\mathrm{BC}$ in black premenopausal women from Carolina breast cancer study $(\mathrm{CBC})[40]$ and a recent report of the cancer Genomic Atlas (TCGA) data analysis in AA women (33\%) [42]. But our finding is significantly lower compared with the white American women in the aforementioned studies (34\% versus15\%) [42]. The TNBC is both clinically and biologically distinct disease. It is more common in younger women, poorly differentiated, invasive ductal carcinoma, no special type which are all present in our case series of TNBCs. Patients with TNBC are not responsive to standard chemotherapy and have a poor outcome. Women with TNBC have lower disease free survival and overall survival in many African American studies. It is also reported that BRCA1/2 mutations are more common in TNBC. TCGA data analysis has reported higher TP53 and MLL3 mutations in black African American than white American women with TNBC but no difference in somatic copy number of mutations [42]. Another study also reported amplification of fibroblast growth factor receptor 2 (FGFR2) genes in TNBC but not in other subtypes. However, the genetic profile of TNBC in indigenous African women is not fully investigated.

The expression of HER2 in this cohort study was remarkably high (28\%); a similar rate have been reported in some African studies and Saudi Arabian women [43] and south Asian [44, 45]. Luminal-A like subtype which is less aggressive type of $\mathrm{BC}$ was less frequent (37\%) in our study population but the proportion is consistent with AA of CBC study [40]. This figure is lower compared to Egypt [38], Morocco [31] some other East African countries but higher compared to West African studies (Nigeria and Senegal) [33]. Previous data from Khartoum reported a higher proportion of luminal A which is comparable to Caucasian women with BC [21], but patients recruited in this study was too small (only one fifth of our study).

It is of note that there is a wide variation in prevalence of HR status, HER2 and their derived intrinsic subtypes of $\mathrm{BC}$ among African women as well as between blacks and whites. Our finding does not fit either to extremely low rates reported in West Africa nor to the remarkably high rate in Eastern and North Africa but consistent with AA. The reason for this racial and regional disparity of subtypes of $\mathrm{BC}$ remained an open question. The potential contributors for this disparity could be technical (quality of tissue fixation, processing, various staining techniques, and different criteria for scoring and reporting). In our cohort, we used similar laboratory methods of evaluation and there is no significant difference in the prevalence of the biomarkers and their derived subtypes in the two countries. It is also possible that the molecular phenotypes of African $\mathrm{BC}$ are biologically diverse and possibly due to different genetic polymorphisms within or among population, as well as 
reproductive pattern and environmental factors. For example, the prevalence of BRCA1/2 mutations is not significantly higher in AA women as compared to Caucasian- American women, in spite of this finding that TNBCs are more frequent in AA [46], suggesting that there are probably other genetic pathways for this molecular subtype. The potential contribution of reproductive related factors is supported by the finding that TNBC in AA women tends to increase with increased parity and younger age at first full-term pregnancy.

There are some limitations to this study: the small sample size from Eritrean women case series, a retrospective clinical data collection and lack of evaluation for HER2+ equivocal results using fluorescent in-situ hybridization (FISH) and not performing Ki67 as a marker of proliferative index. We only considered HER2 positive when IHC score is $3+$ and the actual HER2 positive could be more than the figure we have reported as some of the equivocal (HER2) 2+ might be positive by FISH. Furthermore, not all Sudanese patients were evaluated for HER2 this could affect our inferences.

\section{Conclusion}

In conclusion, breast cancer in Eritrean and Sudanese women is more common in younger age and dominated by more aggressive clinical and molecular prognostic markers. Younger age and poorly differentiated (grade III) tumours are strongly associated with ER negative breast cancer. The luminal-A like which is indolent subtype and sensitive to hormone therapy is less frequent, instead, the most aggressive subtype (TNBCs) are more prevalent in our study group.

\section{Abbreviations \\ AA: African American; BC: Breast cancer; ER: Oestrogen Receptor; HER2: Human Epidermal growth factor Receptor 2; IDCNST: Invasive Ductal Carcinoma No Special Type; IHC: Immunohistochemistry; ILC: Invasive Lobular Carcinoma; PR: Progesterone Receptor; TNBC: Triple Negative Breast Cancer}

\section{Acknowledgements}

The authors are grateful for all staffs of the pathology department of UOG and NHL for their dedication in obtaining data and other technical help.

\section{Funding}

No specific funding for this study.

\section{Availability of data and materials}

The datasets used to generate these results in the current study are available from the corresponding author on reasonable request.

\section{Authors' contributions}

Conception and design: ATS; provision of study materials or patients: ATS, NSHM, AME SB, and AAM; histologic assessment and IHC scoring: ATS, NSHM, SB and AAM; collection and assembly of data: ATS and AME; data analysis and interpretation: ATS and EJK; manuscript writing: ATS, SB, AME and AAM; final approval of manuscript: All authors read and approved for publication.

\section{Ethics approval and consent to participate}

Study was conducted in accordance to the 2011 Declaration of Helsinki. Ethical approval was obtained from both institutions: human research ethics committee, University of Gezira and Orotta School Medicine and Dentistry
(Ref no. HRE/MH0456/11-15). Due to retrospective nature of data collection consent to participate was not sought in this study as previously the patients were consented to be used their clinical samples for general research investigation in the institution and the institutions protocol enforces to get only one general consent.

\section{Consent for publication}

Not applicable

\section{Competing interests}

All authors declared that they have no competing interests.

\section{Publisher's Note}

Springer Nature remains neutral with regard to jurisdictional claims in published maps and institutional affiliations.

\section{Author details}

${ }^{1}$ Pathology Department, Faculty of Medicine, University of Gezira, Wad-Medani, Gezira, Sudan. ${ }^{2}$ Orotta School of Medicine and Dentistry, Asmara, Eritrea. ${ }^{3}$ National Cancer Institute, University of Gezira, Wad-Medani, Gezira, Sudan. ${ }^{4}$ Weill Cornell of Medicine- Qatar, Pathology and Laboratory Medicine, Department of Medical Education, Doha, Qatar. ${ }^{5}$ Department of Gynaecology, Institute of Medical Epidemiology, Biostatistics and Informatcs, Martin-Luther University, (Saale) Halle-Wittenberg, Germany.

Received: 3 October 2016 Accepted: 21 November 2017

Published online: 01 December 2017

\section{References}

1. Siegel RL, Miller KD, Jemal A. Cancer statistics, 2016. CA Cancer J Clin. 2016;66(1):7-30

2. Forman D, Bray F, Brewster DH, Mbalawa GC, Kohler B, Piñeros M, et al. Cancer Incidence in Five Continents Vol. X, in IARC Scientic Publication. Lyon, France: International Agency for Research on Cancer; 2014.

3. Ferlay J, Ervik M, Dikshit R, Eser S, Mathers C, Rebelo M, et al. GLOBOCAN 2012 v1.0. Lyon, France: Cancer Incidence and Mortality Worldwide: IARC; 2012.

4. DeSantis CE, Sauer AG, Kramer JL, Smith RA, Jemal A. Convergence of incidence rates between black and white women. CA Cancer J Clin. 2016;66(1):31-42.

5. Jiagge, E.J, Chitale, D. Bensenhaver D, Awuah, B. Hoenerhoff, M., et al., Comparative analysis of breast cancer phenotypes in African American, white American, and west versus east African patients: correlation between African ancestry and triple-negative breast cancer. Ann Surg Oncol, 2016. 23(12): p. 3843-3849.

6. Brinton LA, Awuah B, Yarney J, Wiafe S, Wood SN, Ansong D, et al. Breast cancer in Sub-Saharan Africa: Opportunities for prevention. Breast Cancer Res Treat. 2014;144(3):467-78.

7. Newman LA. Disparities in breast cancer and African ancestry: a global perspective. Breast Journal. 2015;21(2):133-9.

8. Bowen RL, D.S., Ryan DA, Hart IR, Jones JL, Early onset of breast cancer in a group of British black women. Br J Cancer 2008. 98: p. 277-281.

9. Elledge RMC, Chamness GM, Osborne GC. Tumor biologic factors and breast cancer prognosis among white, hispanic, and black women in the United States. J Natl Cancer Inst. 1994;86(9):705-12.

10. Gukas ID, Girling AC, Mandong BM, Prime W, Jennings BA, Leinster SJA. Comparison of clinicopathological features and molecular markers in British and Nigerian women with breast cancer. Clin Med Oncol. 2008;2:347-51.

11. Eng A, dos-Santos-Silva I. Receptor-defined subtypes of breast cancer in indigenous populations in Africa: a systematic review and meta-analysis. PLoS Med. 2014;11:e1001720.

12. Bird PA, Hill AG, Houssami N. Poor hormone receptor expression in east African breast cancer: evidence of a biologically different disease? Ann Surg Oncol. 2008;15(7):1983-8.

13. Dickens C, Duarte R, Zietsman A, Cubasch H, Kellett P, Schüz J, Kielkowski D, McCormack V, et al. Racial comparison of receptor-defined breast cancer in Southern African women: Subtype prevalence and age - Incidence analysis of nationwide cancer registry data. Cancer Epidemiol Biomarkers Prev. 2014;23(11):2311-21

14. Sayed S, Moloo Z, Wasike R, Bird P, Oigara R, Govender D, et al. Is breast cancer from Sub Saharan Africa truly receptor poor? Prevalence of ER/PR/ HER2 in breast cancer from Kenya. Breast. 2014;23(5):591-6. 
15. Perou CM, Srlie T, Eisen MB, Rijn M, Jeffrey SS, Rees CA, et al. Molecular portraits of human breast tumours. Nature. 2000;406(6797):747-52.

16. Hu Z, Fan C, Oh DS, Marron JS, He X, Qaqish BF, et al. The molecular portraits of breast tumors are conserved across microarray platforms. BMC Genomics. 2006;7

17. Rouzier $R$, et al. Breast cancer molecular subtypes respond differently to preoperative chemotherapy. Clin Cancer Res. 2005;11(16):5678-85.

18. Millikan RC, Tse B, Moorman CK, Conway PG, Smith K, et al. Epidemiology of basal-like breast cancer. Breast Cancer Res Treat. 2008;109(1):123-39.

19. Schneider BP, et al. Triple-negative breast cancer: risk factors to potential targets. Clin Cancer Res. 2008;14(24):8010-8.

20. Galukande $\mathbf{M}$, et al. Molecular breast cancer subtypes prevalence in an indigenous sub Saharan African population. Pan Afr Med J. 2014;17:249.

21. Awadelkarim, KD, Arizzi, C, Elamin, EO, Hamad, HM, De Blasio, P, Mekki, SO et.al. Pathological, clinical and prognostic characteristics of breast cancer in Central Sudan versus Northern Italy: implications for breast cancer in Africa. Histopathology, 2008. 52(4): p. 445-456.

22. Eltaib AM, Saad RZAK. Clinico-pathological features of breast cancer in patients below 50 years of age in Khartoum. Khartoum Med J. 2015;8(3):1158-63.

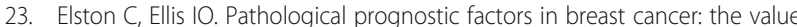
of histological grade in breast cancer: experience from a large study with long-term follow-up. Histopathology. 2002;41:154-61.

24. Sobin LH, Gospodarowicz M, Wittekind C. TNM classification of malignant tumours: John Wiley \& Sons; 2011.

25. Hammond MEH, Hayes DF, Wolff AC, Mangu PB, Temin S. American society of clinical oncology/College of American Pathologists guideline recommendations for immunohistochemical testing of oestrogen and progesterone receptors in breast cancer. J Oncol pract/Am Soc Clin Oncol. 2010;6:195-7.

26. Singh M, Zhang L, Song D, Gong Y, Adams S, Ross DS, et al. Distinct breast cancer subtypes in women with early-onset disease across races. Am J Cancer Res. 2014;4:337-52.

27. Adebamowo, CA, Famooto, A, Ogundiran, TO, Aniagwu, T, Nkwodimmah, C, Akang, EE et.al. Immunohistochemical and molecular subtypes of breast cancer in Nigeria. Breast Cancer Res Treat, 2008. 110(1): p. 183-188.

28. Renato Mariani-Costantini, M.M.A.E., Gitana Maria Aceto, Ahmed Abdalla Mohamedani and Khalid Dafaallah Awadelkarim, Epidemiology, Pathology, Management and Open Challenges of Breast Cancer in Central Sudan: A Prototypical Limited Resource African Setting, in Breast Cancer - From Biology to Medicine. 2017, INTECH open science open mind.

29. Hagos A, Tesfamichael D, Weldu H, Hailemichael M, Eman D, Mehari T. Trends in the incidence of cancer in Eritrean hospitals and Eritrean National Health Laboratory 2000-2010. UK J Pharm Biosci. 2016;4(5):47-55.

30. World Health Organization, Cancer Country Profiles, Eritrea. 2014: http://who.int/cancer/country-profiles/eri_en.pdf.

31. Manal EE, Elidrissi ME, Ouarzane M, Harroudi TE, Afqir S, Bellaoui M. First report on molecular breast cancer subtypes and their clinico-pathological characteristics in Eastern Morocco: series of 2260 cases. BMC Women's Health. 2017;17(3) doi:10.1186/s12905-016-0361.

32. Pang JT, Griffith KA, Awuah B, Newman LA, Kleer CG. Invasive breast carcinomas in Ghana: High frequency of high grade, basal-like histology and high EZH2 expression. Breast Cancer Res Treat. 2012;135(1):59-66.

33. Huo D, Ikpatt F, Khramtsov A, Dangou JM, Nanda R, Dignam J, et al. Population differences in breast cancer: Survey in indigenous african women reveals over-representation of triple-negative breast cancer. J Clin Oncol. 2009;27(27):4515-21.

34. Der EM, Gyasi RK, Tettey Y, Edusei L, Bayor MT, Jiagge E, et al. Triplenegative breast cancer in Ghanaian women: The Korle Bu Teaching Hospital experience. Breast Journal. 2015;21(6):627-33.

35. Ikpatt OP, Ndoma-Egba R. Oestrogen and progesterone receptors in Nigerian breast cancer: relationship to tumour histopathology and survival of patients. Cent Afr J Med. 2003;49(11-12):122-6.

36. Mbonde MP. Expression of estrogen and progesterone receptors in carcinomas of the female breast in Tanzania. Oncol Rep. 2000;7(2):277-83.

37. Galukande, M, Mirembe F, Karamagi C, and Asea, A. Difference in Risk Factors for Breast Cancer by ER Status in an Indigenous African Population. ISRN Oncol, 2013. 2013: p. doi.org/10.1155/2013/463594.

38. El-Hawary A, Ahmed S, Elsayed AA, Zalata KR. Molecular subtypes of breast carcinoma in Egyptian women: Clinicopathological features. Pathol Res Pract. 2012;208(7):382-6.
39. Kantelhardt EJ, Aynalem A, Wondemagegnehu T, Jemal A, Vetter M, et al. The prevalence of estrogen receptor-negative breast cancer in Ethiopia. BMC Cancer. 2014;14(1)

40. Lisa AC, Perou CH, Chad A, Livasy CA, et al. Race, Breast Cancer Subtypes, and Survival in the Carolina Breast Cancer Study. JAMA. 2006;295(21):2492-502.

41. Thakur K, Kunnumakkara D, Ajaikumar B. Alarming Burden of Triple-negative Breast Cancer in India. Clin Breast Cancer. 2017;

42. Foluso OA, Ta Y, Luo J, Weilbaecher $K$, Ma CX. Differences in the mutational landscape of triple-negative breast cancer in African Americans and Caucasians. Breast Cancer Res Treat. 2017;161:491-9.

43. Khawla A-K, Schraml P, Sheikh S, Amr S, Torhorst J, Tapia C, et al. Predominance of high-grade pathway in breast cancer development of Middle East women. Mod Pathol. 2005;18:891-7.

44. Wan D, Villa D, Woods R, Yerushalmi R, Gelmon K, et al. Breast Cancer Subtype Variation by Race and Ethnicity in a Diverse Population in British Columbia. Clin Breast Cancer. 2016;16(3):e49-55.

45. Riyaz B, Sanket S, Yu TG, Moss D, Hill GA. Systematic review of breast cancer biology in developing countries (part 1): Africa, the Middle East, Eastern Europe, Mexico, the Caribbean and South America. Cancers. 2011;3(2):2358-81.

46. Malone KE, Daling JR, Doody DR, Hsu L, Bernstein L, Coates RJ. Prevalence and predictors of BRCA1 and BRCA2 mutations in a population based study of breast cancer in White and Black American. Cancer Res. 2006:66(16):8297-308.

\section{Submit your next manuscript to BioMed Central and we will help you at every step:}

- We accept pre-submission inquiries

- Our selector tool helps you to find the most relevant journal

- We provide round the clock customer support

- Convenient online submission

- Thorough peer review

- Inclusion in PubMed and all major indexing services

- Maximum visibility for your research

Submit your manuscript at www.biomedcentral.com/submit
Biomed Central 